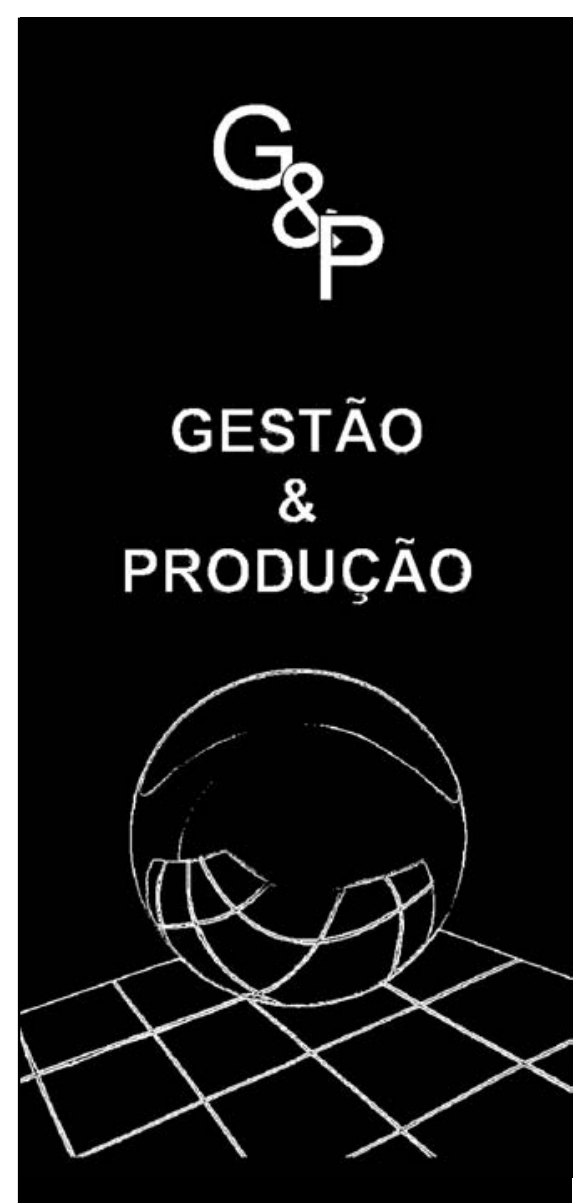

v.8, n.3, p.319-333, dez. 2001

\section{RELAÇÕES ENTRE GRANDES E PEQUENAS EMPRESAS DE AUTOPEÇAS E A DIFUSÃO DE PRÁTICAS DE GESTÃO DA PRODUÇÃO}

\author{
Alessandra Rachid \\ Departamento de Engenharia de Produção - UFSCar \\ E-mail: arachid@power.ufscar.br
}

Ettore Bresciani Filho

Faculdade de Engenharia Mecânica - UNICAMP

E-mail: brescia@lexxa.com.br

Leda Gitahy

Departamento de Política Científica e Tecnológica - UNICAMP

E-mail: leda@ige.unicamp.br

\title{
Resumo
}

Este trabalho analisa a influência de grandes empresas de autopeças na introdução de práticas de gestão da produção em pequenas empresas fornecedoras. A partir de estudos de caso realizados em onze empresas, uma grande empresa de autopeças e 10 fornecedores seus, foi possível identificar um padrão de difusão. Certas práticas, como entrega em just-in-time, certificação e técnicas para controle da qualidade, são mais adotadas por imposição dos clientes. Outras práticas, como o just-in-time interno, as células de manufatura e a polivalência da mão-de-obra são normalmente adotadas por iniciativa das próprias pequenas empresas fornecedoras, ao tomarem os próprios clientes como referência e por influência de outras organizações (consultorias, associações empresariais, instituições de qualificação e treinamento e de financiamento). De uma forma geral, as pequenas empresas têm maior dificuldade de acesso a estas organizações, mas é possível identificar, entre as pesquisadas, aquelas que têm se aproveitado mais destas relações.

Palavras-chave: pequenas empresas fornecedoras, relações entre empresas, redes, gestão da produção.

\section{Introdução}

$\mathrm{D}$ esde o final da década de 70 , vem sendo apontado um conjunto significativo de mudanças na organização da produção que estariam caracterizando um processo de reestruturação industrial. As principais mudanças apontadas por HOFFMAN \& KAPLINSKY (1988) são a introdução dos equipamentos de base microeletrônica, permitindo formas mais 
flexíveis de automação; mudanças na organização do trabalho, com ampliação do conjunto de atividades desenvolvidas pelos trabalhadores; e as novas formas de relação entre empresas clientes e fornecedoras, num processo liderado pela indústria automobilística.

Complementando estas mudanças, observa-se na década de 90 uma forte tendência das grandes empresas reduzirem sua estrutura e terceirizarem atividades, inclusive atividades produtivas. No Brasil, a introdução desse conjunto de mudanças acelera-se com a abertura das importações. Ainda nesta década, a indústria automobilística no país foi alvo de políticas específicas e foi fortemente afetada pela política de estabilização econômica. Diante deste contexto e considerando que essa indústria é disseminadora de práticas de gestão da produção e do trabalho, procura-se avaliar a disseminação destas práticas nas pequenas empresas do setor, analisando de que forma as grandes empresas clientes influenciaram este processo. Também são analisadas as relações das pequenas empresas com outras organizações, como consultorias, associações patronais, instituições de treinamento e de financiamento, procurando construir um quadro mais completo do conjunto de influências que conformam o seu comportamento.

Apesar de existirem muitos estudos sobre as mudanças na gestão da produção e a reestruturação industrial em curso, a maior parte é voltada para grandes empresas, apesar da importância das pequenas empresas para a composição do tecido industrial e para a geração de empregos.

No próximo item são apresentados o método de pesquisa utilizado e as empresas pesquisadas. A perspectiva teórica de redes, utilizada para analisar as relações entre empresas, é apresentada no item 3. O item 4 trata da reestruturação das grandes empresas e analisa quais são as mudanças nas relações entre empresas clientes e fornecedoras. $\mathrm{O}$ item 5 trata especificamente das relações externas das pequenas empresas fornecedoras pesquisadas com empresas clientes e com outras organizações e da influência destas relações na introdução de práticas de gestão da produção. Uma análise mais completa destas questões pode ser encontrada em RACHID (2000).

\section{A Pesquisa}

$\mathrm{E}$ ste trabalho baseia-se em estudos de caso em 11 empresas, uma que produz freios e fornece diretamente para as montadoras, a Freios S/A, e 10 pequenas e médias empresas fornecedoras dela, apresentadas na Tabela 1. Devido ao compromisso de confidencialidade, foram atribuídos os nomes fictícios em função de seu principal produto ou atividade que fornece para a Freios S/A. Esta tem apenas 340 funcionários na unidade visitada, mas é uma multinacional com presença em 18 países, com 5600 empregados, sendo, portanto, considerada uma grande empresa. Todas as empresas localizam-se no eixo São Paulo - Araraquara.

Os estudos de caso são muitas vezes criticados por não permitirem generalizações. Para GRANOVETTER (1984), este é o motivo de existirem poucos estudos em pequenas e médias empresas. Já que não podem generalizar, pesquisadores de diversas áreas acabam apostando nas grandes empresas que, pelo menos de forma isolada, têm maior peso. $\mathrm{O}$ autor acredita que a opção pela grande empresa também se dá em função da influência marxista, que não via a pequena empresa como um espaço onde ocorresse o 'processo de trabalho'. Este viés, de pesquisar apenas grandes empresas, leva a distorções que este trabalho procura diminuir.

Quanto aos estudos de caso, deve-se ressaltar que estes não se propõem a enumerar freqüências, mas permitem a generalização em relação à proposições teóricas. Além disso, são mais adequados para analisar fenômenos complexos, como no caso dos fenômenos organizacionais, que não podem ser controlados pelo pesquisador (YIN, 1994). Cabe ressaltar também que o formato de pesquisa escolhido, de focalizar uma parte de uma cadeia produtiva, permite avaliar melhor o processo de difusão desde as empresas mais dinâmicas (ABRAMO, 1999). A principal 
Tabela 1 - Empresas pesquisadas (1997)

\begin{tabular}{|c|l|c|}
\hline Empresa & \multicolumn{1}{|c|}{ Produto/Atividade } & $\begin{array}{c}\text { Número de } \\
\text { funcionários }\end{array}$ \\
\hline Freios S/A & Sistemas de freios & 340 \\
\hline Estamparia 1 & Estamparia, ferramentaria e injeção de plásticos & 320 \\
\hline Usinagem 1 & Usinagem & 189 \\
\hline Plásticos 1 & Motores, estamparia, usinagem, injeção de plásticos e ferramentaria & 160 \\
\hline Fundição 1 & Pistões, fundição, usinagem e injetados & 130 \\
\hline Usinagem 2 & Usinagem & 54 \\
\hline Usinagem 3 & Usinagem & 40 \\
\hline Ferramentaria 1 & Ferramentaria e usinagem & 38 \\
\hline Usinagem 4 & Usinagem & 9 \\
\hline Equipamentos 1 & Projeto e montagem de equipamentos & 6 \\
\hline Usinagem 5 & Usinagem & 5 \\
\hline
\end{tabular}

fonte de informações foram as entrevistas, mais adequadas para tratar de temas mais complexos, como é o caso da relação entre organizações. As informações relacionadas a este assunto dificilmente seriam fornecidas pelo envio de questionários (ALVES-MAZZOTTI, 1998).

Este artigo utiliza os dados da pesquisa "Reestruturação produtiva trabalho e educação: os efeitos sociais da terceirização Industrial em três regiões do país", CEDES/FINEP/CNPQ, coordenada por Alice Rangel de Paiva Abreu e José Ricardo Ramalho (PPGS/IFCS/UFRJ), Leda Gitahy (DPCT/IG/UNICAMP) e Roberto Ruas (PPGA - UFRGS), (RJ, SP, RS), 1995-1997. Agradecemos a contribuição de Adriana Marques da Cunha e Fabiane Santana Previtalli que participaram da pesquisa realizada na região de Campinas. Para as entrevistas, foram utilizados dois roteiros: um para as entrevistas com gerentes da empresa cliente e o outro para gerentes ou proprietários das empresas fornecedoras. Desta forma, foi possível confrontar a visão dos dois lados da relação. Para efeitos de comparação, também serão utilizados dados de 10 pequenas empresas pertencentes à cadeia de fornecimento da indústria linha branca, pesquisadas no âmbito do mesmo projeto, já que estas também fornecem para o setor de autopeças.

\section{A Perspectiva de Redes}

A relações das pequenas e médias empresas de autopeças com os seus clientes e com outras organizações foram estudadas sob a perspectiva de redes. Esta perspectiva é uma das várias abordagens derivadas da teoria dos sistemas, que concebe a organização como um sistema aberto, envolvida em um ambiente que a influencia e com o qual realiza trocas. A perspectiva de redes avança em relação à teoria dos sistemas ao procurar identificar as outras organizações com as quais a organização estudada se relaciona e ao analisar o padrão destas relações, que podem atuar tanto no sentido de facilitar quanto no de restringir as ações organizacionais (NOHRIA, 1992; NOHRIA \& GULATI, 1994).

O termo rede é empregado por alguns autores para se referir a uma forma particular de organização, uma forma diferente de coordenação da atividade econômica, intermediária entre uma transação de mercado e uma estrutura hierárquica de governança. Numa organização de mercado puro, as relações são esporádicas, criadas para transferência de um bem ou recurso, e depois se desfazem. Numa organização hierárquica, há uma propriedade comum e existe 
uma autoridade administrativa responsável pela coordenação. Já numa organização em rede, existe um conjunto de atores que mantêm relações recorrentes e duradouras, com padrões recíprocos de comunicação e troca, mas não existe a figura da autoridade administrativa (POWELL, 1990).

GRANOVETTER (1985), no entanto, afirma que as relações de mercado puro praticamente não existem. Esta afirmação pode não se aplicar em alguns setores da economia, mas se aproxima bastante da realidade das transações na cadeia de fornecimento da indústria automobilística. Para este autor, todas as ações econômicas, assim como qualquer outra ação humana, realizam-se dentro de redes de relações interpessoais. Desta forma, qualquer conjunto de ligações entre atores, sejam eles indivíduos, organizações ou seus membros, pode ser considerada como uma rede e diversas ações relevantes no campo das organizações têm sido abordadas sob esta perspectiva. As ligações não se restringem às relações formais, como as representadas em organogramas ou fluxogramas, mas envolvem também as relações informais (GRANOVETTER, 1992; NOHRIA, 1992).

Grande parte dos estudos realizados sob a perspectiva de redes procura analisar como as relações (entre indivíduos, organizações ou seus membros) são utilizadas para a mobilização de diferentes formas recursos como, por exemplo, para obtenção de emprego, evolução na carreira e também na difusão de inovações, como no caso deste trabalho. O termo inovação aqui não se refere apenas à invenção, à geração de idéias inéditas, mas também à primeira vez em que uma idéia, técnica ou prática é adotada na unidade em observação, mesmo que já tenha ocorrido em outras unidades antes, de acordo com o conceito utilizado por STONEMAN (1995). A inovação também é vista aqui sob uma perspectiva dinâmica, considerando que as técnicas e práticas sofrem adaptações em cada unidade onde são implantadas (ROSENBERG, 1982).

A perspectiva de redes considera que as fontes externas de conhecimento são sempre críticas para o processo de inovação, que ocorre através de trocas realizadas entre os atores, podendo envolver publicações, programas de computador, artefatos, recursos financeiros e habilidades das pessoas (CALLON, 1992). As relações informais exercem um importante papel neste processo de troca (FAULKNER, 1994). Para as pequenas empresas é especialmente interessante integrar-se num contexto de relações entre empresas, principalmente com grandes empresas, que podem transferir vários recursos, como conhecimento técnico, equipamento, capital, habilidades gerenciais, trabalhadores qualificados e acesso a mercados (SPÄTH, 1993).

A capacidade de aproveitar as fontes externas depende de um certo conhecimento acumulado internamente, até para poder avaliar o potencial de novas técnicas. Grande parte deste conhecimento é tácito e pode ser prejudicado pelas grandes e rápidas trocas de pessoal que têm ocorrido nas grandes empresas (COHEN \& LEVINTHAL, 1990; LANGLOIS \& ROBERTSON 1995). Já as pequenas empresas estão sujeitas a perder este conhecimento em função da dificuldade de estabilizar a mão-deobra, principalmente a mais qualificada, que tende a ser atraída pelos maiores salários das grandes empresas.

As relações externas atuam na difusão de conhecimentos, mas também atuam no sentido de legitimar certas práticas, muitas vezes de forma independente às considerações sobre sua eficiência. As redes fazem com que as pessoas e as organizações ajam de acordo com crenças convencionadas, como uma forma de diminuir as incertezas e também de se obter legitimidade. POWELL \& DIMAGGIO (1991) chamam este comportamento de isomorfismo e apontam que pode ocorrer de diferentes maneiras. À influência exercida por associações profissionais e comerciais na adoção dessas práticas os autores dão o nome de isomorfismo normativo. Também as universidades, os institutos de treinamento, os periódicos especializados e a imprensa de negócios atuam neste sentido ao detalhar 
informações sobre as best practices correntes (POWELL \& SMITH-DOERR, 1994).

Boa parte deste comportamento homogêneo deve-se à influência de organizações consideradas exemplares. A ligação a estas organizações já é uma forma de se buscar a legitimidade, mas também há um esforço para acompanhar as suas ações. Desta forma, muita inovação ocorre pela imitação, o que POWELL \& DIMAGGIO (1991) chamam de isomorfismo imitativo. Existe até um procedimento formal com este objetivo, o benchmarking, pelo qual uma empresa tem acesso às práticas de outra adotada como exemplo (benchmark significa marca de referência).

Em muitas relações, a adoção de uma prática ocorre em função de relações de autoridade, como, por exemplo, uma lei ambiental imposta pelo governo. A esta forma de influência os autores dão o nome de isomorfismo coercitivo.

\section{Reestruturação e Mudança nas Relações entre Empresas}

$\mathrm{O}$ padrão da grande empresa verticalizada consolidado no pós-guerra vem sendo substituído. As grandes empresas têm diminuído sua estrutura pela redução dos níveis hierárquicos, da mudança da divisão em departamentos, da terceirização das atividades, envolvendo desde atividades de apoio até atividades produtivas, e do estabelecimento de novas formas de relação com os fornecedores.

As relações com grandes empresas representam uma das principais formas de inserção das pequenas empresas na economia. Estas podem atuar como fornecedoras, subcontratadas, revendedoras, autorizadas para prestar assistência técnica, franqueadas ou licenciadas das grandes. Com a reestruturação, muitas das atividades terceirizadas representam uma oportunidade para as pequenas estabelecerem ou intensificarem essas relações (SOUZA, 1993a). Isto se comprova no caso da Freios S/A, que terceirizou muitas atividades, principalmente no ano de 1994. Em 1997, dos seus 110 fornecedores de atividades produtivas auditados, apenas 3 eram grandes empresas. Por outro lado, todas as pequenas empresas pesquisadas receberam atividades terceirizadas pela Freios S/A ou por outro cliente, tanto da indústria automobilística quanto de outros setores.

Cabe observar que o processo de terceirização representa uma mudança no perfil do emprego. As empresas com menos de 500 empregados são importantes empregadoras, respondendo por $67,4 \%$ do emprego total e por $59,7 \%$ do emprego na indústria de transformação. No entanto, os salários tendem a diminuir junto com o porte da empresa (IBGE, 1997). Além disso, as pequenas empresas recebem menos atenção dos sindicatos e sua atuação nas grandes empresas fica mais difícil, porque estas passam a abrigar diferentes tipos de trabalhadores em seu espaço, a saber: efetivos; temporários, contratados por meio de empreiteiras tradicionais, como a construção civil; e novas, estagiários, consultores, auditores, autônomos, funcionários dos fornecedores, revendedores em treinamento (SOUZA, 1993a). O mesmo se dá em relação às empresas pesquisadas.

As grandes empresas têm mudado a forma de relacionar com seus fornecedores, muito sob influência de práticas comuns na indústria japonesa, procurando torná-las mais estáveis, com um maior nível de confiança e de troca de informações. Além das exigências relacionadas ao preço, passam a fazer exigências relacionadas à entrega, qualidade e capacidade de projeto. Em troca, são oferecidos contratos de prazos maiores e há uma redução do número de fornecedores, o que caracteriza relações mais estáveis, já que a prática tradicional da indústria automobilística era ter vários possíveis fornecedores por item para facilitar sua substituição (HOFFMAN \& KAPLINSKY, 1988; HELPER, 1991).

$\mathrm{Na}$ década de 90 , paralelamente a essa reestruturação, intensifica-se o global sourcing, ou seja, a cotação em diversos países a partir de escritórios de compras centralizados. Ao mesmo tempo, exige-se que as empresas de autopeças tenham a capacidade de se instalar em diferentes regiões. Em função desta exigência, a Freios S/A 
havia iniciado atividades no Japão em 1993 e na China em 1995. Uma forma particular desta exigência é o follow sourcing: a empresa que fornece uma peça no país aonde o veículo foi lançado deve se instalar aonde o veículo for ser produzido, reforçando a necessidade de organizar as operações em bases internacionais (COSTA, 1998; SALERNO et al., 1998). Como conseqüência, há uma série de fusões e aquisições, aumentando a concentração da estrutura de propriedade do setor. Existe uma previsão de que esta avance ao ponto de que cada segmento de autopeças se concentre em três conglomerados, um norte-americano, um europeu e possivelmente um asiático (ABY-AZAR, 1996).

No Brasil, os Acordos Automotivos de 1992 e 1993, firmados entre sindicatos patronais e de trabalhadores e órgãos públicos federais, estaduais e municipais, levaram ao fim da estagnação que a indústria automobilística enfrentou na década de 80. Em 1993, o número de veículos produzidos superou, pela primeira vez, o volume produzido em 1980 e cresceu continuamente até 1997 (ANFAVEA, 1999).

Em 1995, o governo criou o Regime Automotivo visando atrair investimentos de montadoras e evitar que estes fossem para a Argentina, que já havia adotado uma política neste sentido em 1991. O imposto de importação sobre equipamentos, matérias-primas e componentes foi reduzido para $2 \%$, com previsão de aumentar gradativamente. $\mathrm{O}$ índice de nacionalização foi reduzido de $80 \%$ para $60 \%$.

O movimento de concentração do setor de autopeças observado internacionalmente é reforçado pelo Regime. Este, aliado à atração exercida pelo mercado interno e pelo Mercosul, incentivou o investimento estrangeiro de montadoras e empresas de autopeças já instaladas no país e de ingressantes. No entanto, a taxa de $2 \%$ para importação de peças e componentes, aliada à sobrevalorização do real mantida até o início de 1999, fez com que a importação de autopeças crescesse $520 \%$ entre 1989 e 1997, prejudicando a produção local (SINDIPEÇAS, 1999). Além disso, as taxas de juros do país mantiveram-se elevadas, agravando a situação das empresas dependentes de recursos financeiros internos. Como conseqüência, as grandes empresas de capital nacional tiveram que se associar ou foram vendidas para empresas de capital estrangeiro. A presença do capital nacional no setor ficou cada vez mais restrito a pequenas e, no máximo, médias empresas, com produtos menos sofisticados e de menor valor agregado, no segundo ou terceiro nível da cadeia de fornecimento (ABY-AZAR, 1996; COSTA, 1998).

\section{As Relações Externas das Empresas Pesquisadas}

\section{As relações com as grandes empresas clientes}

$\mathrm{T}$ ambém no Brasil, o padrão de relação entre empresas clientes e fornecedoras vem sofrendo mudanças. AMATO (1995), no entanto, observa algumas diferenças entre as empresas de autopeças e as montadoras, como o menor grau de complexidade das peças compradas, o que leva a menores exigências de qualidade e a maior preocupação com os custos da mão-deobra, que em geral têm maior peso no custo total neste nível da cadeia. As empresas de autopeças ainda não contam com uma rede de fornecedores totalmente confiáveis e, por outro lado, ameaçam constantemente cortar os pedidos, o que dificulta uma melhoria nas relações com seus fornecedores.

A Freios S/A reduziu o número de fornecedores de 250 para 110 , mas continua mantendo dois ou até três fornecedores para certos itens. Entre os entrevistados percebe-se que um menor número de fornecedores facilita uma maior proximidade com as empresas clientes. No caso da Freios S/A, a diminuição do número de fornecedores coincidiu com um aumento das formas de contato. Antes, o contato com fornecedores envolvia apenas o departamento de compras da Freios S/A. Atualmente, envolve também as áreas de logística e qualidade.

Aumentaram também as exigências relacionadas à qualidade, ao prazo e freqüência de entrega. 
Apesar disto, a pressão sobre os preços estava muito forte e as empresas estavam tendo de diminuir seus preços, principalmente dos itens fornecidos para os clientes do setor de autopeças, que também estavam sendo pressionados em função da baixa taxa de importações e da sobrevalorização do real, conforme já exposto. Em São Paulo, o setor reduziu seus preços entre $14 \%$ a $17 \%$ de 1994 a 1998, segundo declaração do vice-presidente do SINDIPEÇAS, o Sindicato Nacional da Indústria de Componentes para Veículos Automotores (PINHEIRO, 1998). Vários entrevistados apontaram que desde 1994 o seu preço só havia sofrido reajustes para baixo. Segundo o entrevistado na Usinagem 1, houve uma redução média de $30 \%$ dos seus preços.

Mesmo entre as que cumpriam as demais exigências e eram certificadas pelos clientes, havia o receio de que fossem substituídas por concorrentes de menor preço, o que de fato havia acontecido com um fornecedor da Freios S/A visitado em uma pesquisa anterior (Projeto "Capacitação de Pequenas Empresas na Região de Campinas", UNICAMP/SEBRAE, 19931994). A referência para o preço baseava-se na cotação internacional, o chamado preço objetivo. A própria Freios S/A já contava com uma relação de 67 fornecedores auditados por outras unidades e que deveriam substituir fornecedores nacionais.

Entre as empresas pesquisadas, apenas as ferramentarias têm contratos formais com os clientes. Com as outras, existe apenas o chamado 'pedido de compra'. Com exceção da Equipamentos 1 e da Usinagem 5, os entrevistados em todas as empresas mencionaram casos de cancelamento de pedidos de itens já produzidos. $\mathrm{Na}$ maioria destes casos, o fornecedor negocia para realizar a entrega destes itens de forma parcelada. Embora seja raro, já houve casos em que as peças produzidas viraram sucata, como na Usinagem 2. Mesmo a Ferramentaria 1, que tinha contrato, não o usava em casos de cancelamento de pedidos por parte de clientes. Segundo o entrevistado, "se o fornecedor acionar o cliente, deixa de atuar no mercado".
A existência de contratos formais nem sempre é de interesse dos fornecedores, pois podem conter cláusulas que dificilmente poderiam cumprir. A Plásticos 1, por exemplo, evita ter contratos com clientes do setor de autopeças, devido às cláusulas sobre multas, que o entrevistado considera muito pesadas. "Não cabem no nosso porte."

\section{A influência das empresas clientes}

Apesar dos problemas apresentados, estas relações são muito importantes para as pequenas empresas. O próprio surgimento de muitas das pesquisadas está ligado a uma grande empresa na qual o proprietário adquiriu experiência antes de fundar a sua. Além disso, a ausência de relações de confiança e de longo prazo não impede a difusão de práticas de gestão da produção. As grandes empresas clientes exigem a implantação de diversas técnicas, apresentadas adiante, e também oferecem algumas formas de apoio, como cursos e material didático, indicação de consultores, o pagamento adiantado, o uso de laboratórios, empréstimo de equipamentos, ajuda no desenvolvimento do processo e compra conjunta de insumos, principalmente quando estes são importados.

Os entrevistados que mais enfatizaram os apoios recebidos foram os da Usinagem 1 e da Plásticos 1. Segundo o entrevistado da Usinagem 1, "hoje a empresa fornecedora é parte integrante deles [dos clientes]. Há uma relação mais interdependente. Eles mandam buscar técnicos até no exterior para nos ajudar." O entrevistado da Plásticos 1 declarou ter relações de 'parceria' com uma empresa cliente produtora de faróis, que sempre está disponível para passar informações. "Vieram ministrar cursos. Em um ano teve uns 20 treinamentos."

A principal forma de apoio, no entanto, citada em todas as empresas, ocorre pelo contato informal, principalmente com a área da qualidade dos clientes. As relações informais que ocorrem entre as pessoas de diferentes organizações tornam a informação mais digna de crédito e mais fácil de 
ser interpretada, agregando-lhe um valor maior do aparente, o que facilita a coordenação e o aprendizado, como aponta UZZI (1996). Segundo o entrevistado na Usinagem 4, a ampliação dos canais de comunicação "implica em um contato mais constante, um entrosamento mais direto com o pessoal da qualidade" que não existia antes, quando o contato ocorria apenas com a área de compras. Segundo ele, isto ajudou a melhorar o desempenho de sua empresa.

A exigência e o apoio oferecido, no entanto, ocorrem de forma seletiva. São exigidas:

- entregas mais freqüentes, permitindo a redução dos estoques nas empresas clientes, segundo o princípio do just-in-time;

- diversas técnicas para controle da qualidade;

- certificações realizadas pelas próprias empresas clientes e pela norma ISO 9000.

Todas estas práticas haviam sido implantadas em todas as pequenas empresas fornecedoras pesquisadas, com exceção da ISO 9000 na Usinagem 5. Esta, por se recusar a se certificar pela ISO 9000, ia perder um dos seus três clientes. (Normas complementares à ISO, como a QS 9000, ainda não eram muito difundidas e foi mencionada apenas pela Usinagem 1, que estava se preparando para certificação.). Esta forma de influência na adoção de práticas caracteriza o que POWELL \& DIMAGGIO (1991) chamam de isomorfismo coercitivo. O que se pode observar é que as técnicas e práticas exigidas são justamente aquelas técnicas e práticas nas quais o caráter de controle é mais forte sem implicar necessariamente num aumento da eficiência produtiva do fornecedor.

Já outras práticas, embora também levem à melhoria no atendimento ao cliente, estavam sendo implantados mais por iniciativa própria das pequenas empresas pesquisadas. São implantados por iniciativa das próprias empresas:

- just-in-time interno. Implantado na Usinagem

1, Plásticos 1, Ferramentaria 1 e Usinagem 5 e em implantação na Estamparia 1;

- células de manufatura. Implantadas na Usinagem 1, Fundição 1, Usinagem 2 e em implantação na Estamparia 1;
- polivalência dos operários diretos. Implantada em todas as empresas fornecedoras, com exceção da Usinagem 2, onde foi implantada, mas depois retirada.

Nestes casos, a influência das grandes empresas clientes ocorre de forma indireta. Nenhum cliente as exige, mas são percebidas como uma necessidade imposta pelo mercado. Também pode ser enquadrada como uma necessidade desta natureza a implantação de equipamentos de base microeletrônica, presentes em todas as empresas, com exceção da Usinagem 4 e da Usinagem 5.

A implantação de algumas destas práticas, as não exigidas, enfrenta dificuldades impostas pelas próprias empresas clientes, como é o caso introdução do just-in-time interno. Mesmo os fornecedores que implantaram o just-in-time em sua produção, como é o caso da Usinagem 1, têm de manter estoques de produto final para se precaver dos "pedidos relâmpagos" dos clientes, expressão utilizada pelo entrevistado da Usinagem 3. Segundo o entrevistado da Ferramentaria 1, houve o repasse dos estoques para os fornecedores. Os clientes dizem que tem just-in-time, mas "não há nenhum tipo de programação para entregas. É tudo no sufoco."

Mas mesmo nestes casos, as práticas utilizadas pelas grandes empresas clientes são usadas como referência.

A possibilidade de adotar as grandes empresas clientes como referência para adoção de práticas de gestão da produção é melhor aproveitada pelas empresas fornecedoras cujo faturamento provém de um número maior de clientes. É o caso da Plásticos 1, que tem o faturamento pulverizado. Isto ocorre porque a empresa tem produto próprio, os motores fora de norma, que atende a um segmento específico de mercado e não são atraentes para os grandes produtores. Além disso, a empresa lançou outros produtos e passou a oferecer serviços produtivos, aproveitando o mercado aberto pelas terceirizações. Outras empresas também têm adotado a estratégia de diversificação para diminuir a dependência em relação a um pequeno número 
de clientes. O proprietário da Usinagem 2 pensa em abrir uma fundição porque "quem compra quer peça pronta, e não comprar fundido de um e ter que mandar usinar em outro." Partindo do mesmo argumento, a Fundição 1 só fornecia peça fundida e agora também realiza a usinagem.

Com o faturamento menos concentrado, as empresas fornecedoras ficam menos sujeitas à imposição de um cliente em particular e, ao mesmo tempo, têm mais chance de ter acesso às práticas vigentes e à troca de informações sobre a experiência e o aprendizado por que passaram os diferentes clientes, que podem apontar quais os macetes, a real utilidade e os limites das diferentes técnicas e práticas. Isto pode ser observado, por exemplo, nos casos da Plásticos 1 e da Usinagem 1, que têm recorrido bastante à ajuda de clientes, conforme já citado. Nesses casos, reforça-se o isomorfismo imitativo. No entanto, muitas das empresas pesquisadas são dependentes de um pequeno número de clientes, como pode ser visto no Tabela 2.

Nestes casos, reforça-se o caráter de interferência e a imposição de práticas e técnicas e, portanto, o isomorfismo coercitivo. A exceção é a Equipamentos 1 que, apesar de ter $90 \%$ do seu faturamento vindo da Freios S/A, não sofre muitas exigências quanto à implantação de técnicas. Isto ocorre em função do serviço especializado que presta. A empresa faz projetos de equipamentos com características específicas para cada cliente e recentemente passou também a montar os equipamentos devido à dificuldade dos clientes encontrarem empresas que o fizessem.

Mas mesmo entre as empresas pesquisadas que têm poucos clientes, foi possível identificar aquelas que compensam esta limitação buscando outras fontes de inovação, o que será explorado a seguir.

\section{Outras relações externas}

Também foram pesquisadas as relações com outras empresas do mesmo porte e com organizações e instituições voltadas para financiamento, qualificação e treinamento, consultoria e representação empresarial. A influência destas organizações na adoção de práticas configura o isomorfismo normativo.

A associação para a realização de ações conjuntas e coordenadas pode criar vantagens que as pequenas empresas não conseguiriam se agissem individualmente. Esta é a principal alternativa para fugir da assimetria de poder com as grandes empresas e adquirir externamente algumas economias que as grandes empresas conseguem internamente. Algumas das possíveis formas de associação são o compartilhamento de recursos, como ferramentas e equipamentos ou a realização de atividades conjuntas, como compras, treinamento, distribuição, pesquisa, exportação, cujos custos são muitas vezes inviáveis para uma pequena empresa isolada (LOVEMAN \& SENGENBERGER, 1990; SPÄTH, 1993).

Apesar das possíveis vantagens, as empresas pesquisadas têm pouco contato com outras pequenas empresas. Para SOUZA (1993b), um dos motivos da falta de associação é o processo seletivo e eliminatório realizado pelos clientes, que joga um fornecedor contra outro. No entanto, é difícil distinguir o quanto esta pressão é causa ou conseqüência da falta de associação. $\mathrm{O}$ fato dos fornecedores não serem organizados entre si favorece as empresas clientes, que podem jogar um fornecedor contra o outro, pressionando-os para abaixarem o preço. A Usinagem 1, por exemplo, só estabelece relações com outras empresas concorrentes de maneira informal "porque se o cliente souber, vai achar que os fornecedores estão combinando preço." Chama a atenção também a aversão ao "sócio", que se estende à possibilidade de associação entre empresas.

Esta dificuldade de associação é menor em cadeias compostas por empresas especializadas. Isto ficou claro no caso da Equipamentos 1, que tinha um acordo com uma empresa produtora de equipamentos eletrônicos. Esta passa os projetos e a montagem da parte mecânica para a Equipamentos 1, que se compromete a comprar os seus componentes eletrônicos. 
Tabela 2 - Distribuição do faturamento das empresas pesquisadas

\begin{tabular}{|c|c|c|}
\hline Empresa & Produtos dos principais clientes & $\%$ faturamento \\
\hline \multirow[t]{4}{*}{ Estamparia 1} & automóveis & 30 \\
\hline & automóveis & 30 \\
\hline & Freios S/A & 10 \\
\hline & Total & 70,0 \\
\hline \multirow[t]{7}{*}{ Usinagem 1} & freios & 20 \\
\hline & eletro-eletrônicos & 18 \\
\hline & refrigeradores & 18 \\
\hline & máquinas de costura & 4 \\
\hline & máquinas de reprografia & 5 \\
\hline & Freios S/A & 2 \\
\hline & Total & 67,0 \\
\hline \multirow[t]{5}{*}{ Plásticos 1} & produtora de equipamentos para escritório & 22 \\
\hline & faróis & 15 \\
\hline & eletrônicos para autos & 3 \\
\hline & Freios S/A & 2 \\
\hline & Total & 42,0 \\
\hline \multirow[t]{6}{*}{ Fundição 1} & transmissores & 39 \\
\hline & eletro-eletrônicos & 12 \\
\hline & Freios S/A & 9 \\
\hline & bicicletas & 7 \\
\hline & equipamentos odontológicos & 5 \\
\hline & Total & 72,0 \\
\hline \multirow[t]{4}{*}{ Usinagem 2} & refrigeradores & 80 \\
\hline & Freios S/A & 15 \\
\hline & eletrônicos para autos & 5 \\
\hline & Total & 100,0 \\
\hline \multirow[t]{6}{*}{ Usinagem 3} & Freios S/A & 20 \\
\hline & refrigeradores & 20 \\
\hline & amortecedores & 20 \\
\hline & limpadoras de pressão & 20 \\
\hline & máquinas de costura & 10 \\
\hline & Total & 90,0 \\
\hline \multirow[t]{4}{*}{ Ferramentaria 1} & eletrônicos para autos & 25 \\
\hline & elevadores & 10 \\
\hline & Freios S/A & 2 \\
\hline & Total & 37,0 \\
\hline \multirow[t]{4}{*}{ Usinagem 4} & Freios S/A & 70 \\
\hline & motores elétricos & 20 \\
\hline & não identificado & 10 \\
\hline & Total & 100,0 \\
\hline Equipamentos 1 & Freios S/A & 90 \\
\hline \multirow[t]{4}{*}{ Usinagem 5} & Freios S/A & 40 \\
\hline & eletrônicos para autos & 50 \\
\hline & máquinas de costura & 7 \\
\hline & Total & 97,0 \\
\hline
\end{tabular}


Os contatos externos são importantes para mobilizar recursos que não podem ser gerados internamente, mas, de uma forma geral as pequenas empresas têm maior dificuldade de acesso às diferentes organizações e instituições. Isto é particularmente agudo no que diz respeito ao acesso a financiamentos, subsídios e incentivos. Apenas um dos entrevistados mencionou ter recebido financiamento de órgãos públicos, no caso, a Plásticos 1, que tem máquinas financiadas pelo FINAME.

Quanto aos sindicatos patronais, a maioria dos entrevistados confirma a afirmação de que estão mais "preocupados com as grandes" empresas, semelhante ao que ocorre com os sindicatos de trabalhadores.

Indagados especificamente sobre o SEBRAE (Serviço Brasileiro de Apoio às Micro e Pequenas Empresas), uma das principais instituições de apoio às pequenas empresas no país, seis dos dez entrevistados não souberam responder a questão ou disseram desconhecer as suas formas de apoio (Estamparia 1, Usinagem 1, Usinagem 4, Ferramentaria 1, Usinagem 3 e Equipamentos 1). Para um entrevistado de uma empresa de galvanoplastia (pertencente à outra cadeia de fornecimento da indústria de linha branca pesquisada no âmbito do mesmo projeto), o tipo de apoio oferecido "não serve para quem já domina a tecnologia". Esta afirmação aponta para uma dificuldade de uma organização voltada para as pequenas empresas: estas atuam nas mais diversas atividades e é difícil ter um programa de apoio que atenda todas as necessidades. Uma possível solução talvez fosse a ligação com organizações setoriais, como a que o SEBRAE fez com o SINDIPEÇAS, com o objetivo de investir na competitividade das pequenas empresas do setor de autopeças, mas cujos resultados não puderam ser avaliados, pois havia se iniciado depois de terminada a pesquisa em que se baseia este texto.

No que diz respeito à qualificação, os técnicos e operários mais qualificados tendem a ser atraídos pelas grandes empresas, que oferecem salários maiores. Este mesmo motivo faz com que sejam poucas as pequenas empresas que contratam pessoas com formação universitária, como pode ser visto na Tabela 3, na qual aparecem as empresas que apresentaram dados a este respeito.

Ainda no que diz respeito à qualificação, as pequenas empresas têm dificuldades para criar programas internos de treinamento e a busca de contato com outras instituições é de fundamental importância. A Tabela 4 mostra alguns cursos citados pelos entrevistados. Estes cursos têm sido realizados a partir de contatos com fornecedores, universidades, escolas de $1^{\underline{0}}$ e $2^{\underline{o}}$ grau, consultorias, SEBRAE, SENAI e uma fundação municipal, o Parque Tecnológico, de uma das cidades onde se localizam as empresas.

Cabe ainda ressaltar um outro papel desempenhado pelo SENAI. Esta instituição foi criticada por entrevistados na Freios S/A e na Fundição 1, por estar desatualizado, mas a instituição é bem avaliada em outras empresas. Seus egressos são os preferidos para recrutamento e muitas empresas utilizam os seus cursos, como exposto na Tabela 4. Além disso, em todas as empresas que forneceram informação a respeito, os proprietários são formados no SENAI ou em outros colégios técnicos, a maioria na área de mecânica. Isto mostra a importância da formação técnica para este perfil de empresa.

A contratação de empresas de consultoria pelas grandes empresas de autopeças é uma prática corriqueira, mas as empresas menores não têm como arcar com os altos custos destas. A sua contratação, quando ocorre, é de forma bastante criteriosa. Algumas têm contratado consultoria para ajudá-las na certificação pela norma ISO 9000, que dificilmente podem ser conduzidas apenas com os recursos internos. Isto foi observado na Fundição 1 e na Estamparia 1. Uma alternativa mais acessível de consultoria tem sido representada por algumas universidades. A Usinagem 2, por exemplo, conta com a consultoria de professores das universidades públicas locais.

O contato com as organizações que ofereceram cursos, apresentadas na Tabela 4, e com 
Tabela 3 - Empregados com formação universitária

\begin{tabular}{|c|c|c|}
\hline Empresa & $\begin{array}{c}\text { Número de } \\
\text { empregados }\end{array}$ & $\begin{array}{c}\text { \% com formação } \\
\text { universitária }\end{array}$ \\
\hline Freios S/A & 340 & 24,4 \\
\hline Ferramentaria 1 & 320 & 14,7 \\
\hline Usinagem 1 & 189 & 6,0 \\
\hline Usinagem 3 & 40 & --- \\
\hline Usinagem 4 & 9 & --- \\
\hline Usinagem 5 & 5 & --- \\
\hline
\end{tabular}

Tabela 4 - Cursos realizados por outras instituições

\begin{tabular}{|c|c|c|}
\hline Empresa & Cursos & Instituição \\
\hline Estamparia 1 & $\begin{array}{l}\text { supletivo } \\
\text { ISO } 9000\end{array}$ & $\begin{array}{l}\text { escolas de } 1^{\circ} \text { e } 2^{\circ} \text { grau } \\
\text { Consultoria } \\
\text { SENAI }\end{array}$ \\
\hline Usinagem 1 & & SENAI \\
\hline Fundição 1 & $\begin{array}{l}\text { qualidade, segurança } \\
\text { qualidade, auditoria interna, } 5 \mathrm{~S}\end{array}$ & $\begin{array}{l}\text { SENAI } \\
\text { Consultorias }\end{array}$ \\
\hline Usinagem 2 & $\begin{array}{l}\text { FMEA } \\
\text { ISO } 9000 \\
\text { multiplicadores } \\
5 S \\
\text { CEP }\end{array}$ & $\begin{array}{l}\text { Universidade Federal } \\
\text { Parque Tecnológico } \\
\text { SENAI } \\
\text { USP }\end{array}$ \\
\hline Usinagem 5 & ISO 9000 & SEBRAE e UNICAMP \\
\hline
\end{tabular}

empresas de consultoria foram as principais influências para adoção de práticas. A partir dos dados disponíveis, observa-se que estas relações têm se concentrado em técnicas voltadas para qualidade e para certificações pela ISO 9000.

Pode-se observar ainda que, apesar das restrições sofridas pelas pequenas empresas, existem aquelas que buscam estabelecer diferentes contatos e, por isto, acabam desenvolvendo melhores condições para adotar e implantar técnicas de acordo com suas necessidades. Este é o caso da Usinagem 2, que tem recorrido a diferentes instituições. A empresa, além de estar desenvolvendo internamente um programa de computador para controlar a programação da produção, também estava se certificando com auxílio de instituições locais. Esta empresa conta com algumas condições privilegiadas, por se localizar numa cidade com duas universidades públicas e um Parque Tecnológico que também presta serviços para outras empresas além daquelas que abriga. No entanto, uma empresa fornecedora da cadeia de linha branca que atua no mesmo ramo, tem o mesmo porte e é localizada na mesma cidade, não recorre a estas instituições. Isto ilustra bem 
como as ações das organizações devem ser entendidas tanto pelo conjunto de restrições impostas pelo seu ambiente quanto por suas respostas diferenciadas às oportunidades existentes.

\section{Conclusões}

$\mathrm{F}$ oram analisadas as relações externas de pequenas empresas pertencentes à cadeia de fornecimento da indústria automobilística. Analisou-se de que forma as relações externas com suas grandes empresas clientes e com outras organizações e instituições influenciam a adoção de técnicas e práticas de gestão da produção. Escolheu-se, para analisar o conjunto de relações das pequenas empresas pesquisadas, a perspectiva teórica de redes, que tem sido bastante utilizada para analisar diferentes formas de relações sociais e do comportamento organizacional.

Foram analisados diferentes aspectos das relações entre pequenas empresas fornecedoras e grandes empresas clientes para avaliar se as 'novas formas de relação' encontram-se presentes. Observou-se que se ampliaram as formas de contato, mas as relações não se caracterizam como relações de confiança nem de longo prazo. A ausência destas características nas relações, no entanto, não impediu a difusão de técnicas e práticas. A ligação com as grandes empresas clientes, em especial com as pertencentes à indústria automobilística, representa para as pequenas empresas uma importante forma de acesso a informações sobre as práticas vigentes.

A análise dos dados sobre as práticas adotadas pelas pequenas empresas permitiu a identificação de um padrão de difusão a partir das grandes empresas clientes. As técnicas para controle da qualidade, a entrega em just-in-time e as diferentes formas de certificação são adotadas por imposição dos clientes, caracterizando o isomorfismo (ação de acordo com crenças ou práticas convencionadas) coercitivo. Isto é evidenciado pelo fato da única empresa não certificada pela ISO 9000 estar excluída do conjunto de fornecedores de uma de suas empresas clientes. Pode-se observar também que estas técnicas são aquelas que reforçam principalmente o repasse de custos e os aspectos de controle sobre os fornecedores.

Outras práticas são implantadas por iniciativa das pequenas empresas pesquisadas, entre as quais destacam-se o just-in-time interno, as células de manufatura e a polivalência dos operários diretos. Nestes casos as empresas clientes também exercem um papel importante, pois são usadas como referência, caracterizando o isomorfismo imitativo. Isto ficou ainda mais claro no caso das pequenas empresas com um maior número de clientes, que estão em condições mais vantajosas também no que diz respeito ao acesso à informação. As pequenas empresas com um menor número de clientes, normalmente as de menor porte e que prestam serviços menos especializados, acabam sofrendo a influência dos clientes de uma forma mais coercitiva.

Existem ainda outras relações externas que influenciam o comportamento das pequenas empresas. Foram analisadas suas relações com outras pequenas empresas, mas observou-se que estas associações são raras e que há uma grande resistência neste sentido. Também foram analisadas as relações das pequenas empresas fornecedoras com instituições que atuam em diferentes áreas. A influência destas outras organizações caracteriza o isomorfismo normativo e, no caso das empresas pesquisadas, têm privilegiado técnicas voltadas para a qualidade.

De uma forma geral, as pequenas empresas têm maior dificuldade de acesso às instituições, seja em função da menor disponibilidade de recursos, seja porque estas têm sua atenção concentrada nas grandes empresas. Apesar das dificuldades, existem entre as pequenas empresas pesquisadas aquelas que têm se aproveitado mais das relações com outras instituições, mesmo entre as de menor porte, e que, em função disto, têm tido maior facilidade para implantar as práticas vigentes. 


\section{Referências Bibliográficas}

ABRAMO, L.: "Cadeias produtivas, segmentação de gênero e novas formas de regulação: notas metodológicas a partir de uma experiência de pesquisa”. In: Seminário Temático Interdisciplinar "Os estudos do trabalho: novas problemáticas, novas metodologias e novas áreas de pesquisa", CEBRAP, USP e UNICAMP, 1999. 10p. <www.sociologia-usp.br/seminari.htm>

ABY-AZAR, C.: "Mais fusões no setor de autopeças”. Gazeta Mercantil, p.C-4, 11 de julho, 1996.

ALVES-MAZZOTTI, A.J.: “O método nas ciências sociais". In: ALVES-MAZZOTTI, A.J. \& GEWANDSZNAJDER, F. $O$ método nas ciências naturais e nas ciências sociais. São Paulo, Ed. Pioneira, 1998. p.107-203.

AMATO NETO, J.: "Reestruturação Industrial, Terceirização e Redes de Subcontratação". Revista de Administração de Empresas, São Paulo, FGV, v.35, n.2, p.33-42, mar-abr 1995.

ANFAVEA: Anuário estatístico da indústria automobilística brasileira - Edição 1999. São Paulo, Anfavea, 1999.

CALLON, M.: "The dynamics of techno-economic networks". In: COOMBS, R.; SAVIOTTI, P. \& WALSH, V. Technological change and company strategies: economical and sociological perspectives. London, Harcourt Brace Jovanovich Publishers, 1992, p.72-102.

COHEN, W.M. \& LEVINTHAL, D.A.: “Absorptive capacity: a new perspective on learning and innovation". Administrative Science Quarterly, v.35, p.128-152, Mar. 1990.

COSTA, I.: $O$ setor de autopeças no Brasil: desafios e mudanças na década de noventa, Campinas, Departamento de Política Científica e Tecnológica, UNICAMP, 1998. 132p. (Dissertação de mestrado)

FAULKNER, W.: “Conceptualizing knowledge used in innovation: a second look at the sciencetechnology distinction and industrial innovation". Science, Technology, \& Human Values, v.19, n.4, p.425-458, Autumn 1994.

GRANOVETTER, M.: "Small is bountiful: labor markets and establishment size". American Sociological Review, v.49, n.3, p.323-334, 1984.
: "Economic action and social structure: the problem of embeddedness". American Journal of Sociology, v.91, n.3, p.481-510, 1985.

: "Problems of explanation in economic sociology". In: NOHRIA, N. \& ECCLES, R.G. (org.) Networks and Organizations, Harvard Business School Press, p.25-56, 1992.

HELPER, S.: "How much has really changed between U.S. automakers and their suppliers?" Sloan Management Review, v.32, n.4, p.15-28, 1991.

HOFFMAN, K. \& KAPLINSKY, R.: Driving Force: The Global Reestruturing of Technology, Labour and Investment in the Automobile and Components Industries. Westview, Boulder, 1988.

IBGE: Estrutura produtiva empresarial brasileira 1994 - Resultados do Censo Cadastro 1995, IBGE, Rio de Janeiro, 1997.

LANGLOIS, R.N. \& ROBERTSON, P.L.: Firms, markets and economic change. London/New York, Routledge, 1995.

LOVEMAN, G. \& SENGENBERGER, W.: "Introduction: economic and social reorganisation in the small and medium-sized enterprise sector". In: LOVEMAN, G.; SENGENBERGER, W. \& PIORE, M.J. (eds.) The re-emergence of small enterprises. Geneva, ILO, International Institute for Labour Studies, p.1-61, 1990.

NOHRIA, N.: "Is a network perspective a useful way of studying organizations?" In: NOHRIA, N. \& ECCLES, R.G. (org.) Networks and Organizations. Cambridge, Harvard Business School Press, p.1-22, 1992.

NOHRIA, N. \& GULATI, R.: "Firms and their environments". In: SMELSER, N.J. \& SWEDBERG, R. (eds.) Handbook of Economic Sociology. Princeton, Russell Sage Fundation, p.529-555, 1994.

PINHEIRO, L.: “Autopeças temem quebrar com alta de juros". O Estado de São Paulo, 20-09, p.B-10, 1998.

POWELL, W.W.: "Neither market nor hierarquy: networks forms of organization". In: CUMMINGS, L.L. \& SHAW, B. (eds.) Research in Organizacional Behavior. Greenwich, CT: JAI Press, v.12, p.295-336, 1990. 
POWELL, W.W. \& DIMAGGIO, P.J.: "The iron cage revisited: institutional isomorfism and collective rationality in organizational fields". In: The new institutionalism in organizacional analysis. The University of Chicago Press, p.63-82, 1991.

POWELL, WW. \& SMITH-DOERR, L.: "Networks and Economic Life". In: SMELSER, N.J. \& SWEDBERG, R. (eds.) Handbook of Economic Sociology. Princeton, Russell Sage Fundation, p.368-402, 1994.

RACHID, A.: Relações entre grandes e pequenas empresas de autopeças: um estudo sobre a difusão de práticas de organização da produção. FEM-UNICAMP, Campinas, 2000. 144p. (Tese de doutorado)

ROSENBERG, N.: Inside the black box: technology and economics. Cambridge University Press, 1982.

SALERNO, M.; ZILBOVICIUS, M.; ARBIX, G. \& DIAS, A.V.C.: "Mudanças e persistências no padrão de relações entre montadoras e autopeças no Brasil". Revista de Administração, v.33, n.3, p.16-28, jul/set 1998.

SINDIPEÇAS (1999): Desempenho do setor de autopeças - 1998. 31p. <www.sindipecas.org.br>
SOUZA, M.C.A.F.: Pequenas e médias empresas na reestruturação industrial. Instituto de Economia, UNICAMP, Campinas, 1993a. 270p. (Tese de doutorado).

: Cooperação Interempresas e Difusão de Inovações Organizacionais. Relatório do Projeto Desenvolvimento Tecnológico e Competitividade da Indústria Brasileira. Campinas, IE-UNICAMP, 1993b.

SPÄTH, B. (ed.): Small firms and development in Latin America - The role of the institutional enviroment, human resources and industrial relations. Geneva, International Institute for Labour Studies, 1993.

STONEMAN, P. (org.): Handbook of the economics of innovation and technological change. Oxford, Blackwell, 1995.

UZZI, B.: "The sources and consequences of embeddednes for the economic performance of organizations: the network effect". American Sociological Review, v.61, p.674-698, 1996.

YIN, R.K.: Case study research: design and methods. $2^{\mathrm{a}}$ edição. Thousand Oaks, California, Sage Publications, 1994.

\title{
RELATIONS BETWEEN SMALL AND LARGE AUTO PARTS MANUFACTURERS AND THE DIFFUSION OF PRODUCTION MANAGEMENT PRACTICES
}

\begin{abstract}
This paper analyzes the influence of large auto parts manufacturers on the introduction of production organization practices at small supplier companies. Case studies taken in eleven companies, i.e., one large auto parts manufacturer and ten of its suppliers, allow to identify a diffusion pattern. Certain practices are more adopted by the buyers' imposition. On the other hand, other practices are usually adopted by initiative of the own small companies. Small companies suffer other influences from their buyers, which are also used as references, and there is also the influence of other organizations (consulting, managerial associations, qualification and training and financing institutions). Small companies have difficulties to access these institutions, but there are those which make better use of such relations.
\end{abstract}

Key words: small-medium suppliers, buyer-supplier relations, production management. 